\title{
CADERNETA DE SAÚDE DA PESSOA IDOSA INSTITUCIONALIZADA: ESTRATÉGIAS PARA ATENÇÃO À SAÚDE INTEGRAL
}

Autores: Miria M. de Morais [1]; Riane T. Ursulino [1] ; Thaiza T. X. Nobre [1] ; Thiago S. Bezerra [1] ; Vilani M. A.Nunes ${ }^{[2]}$.

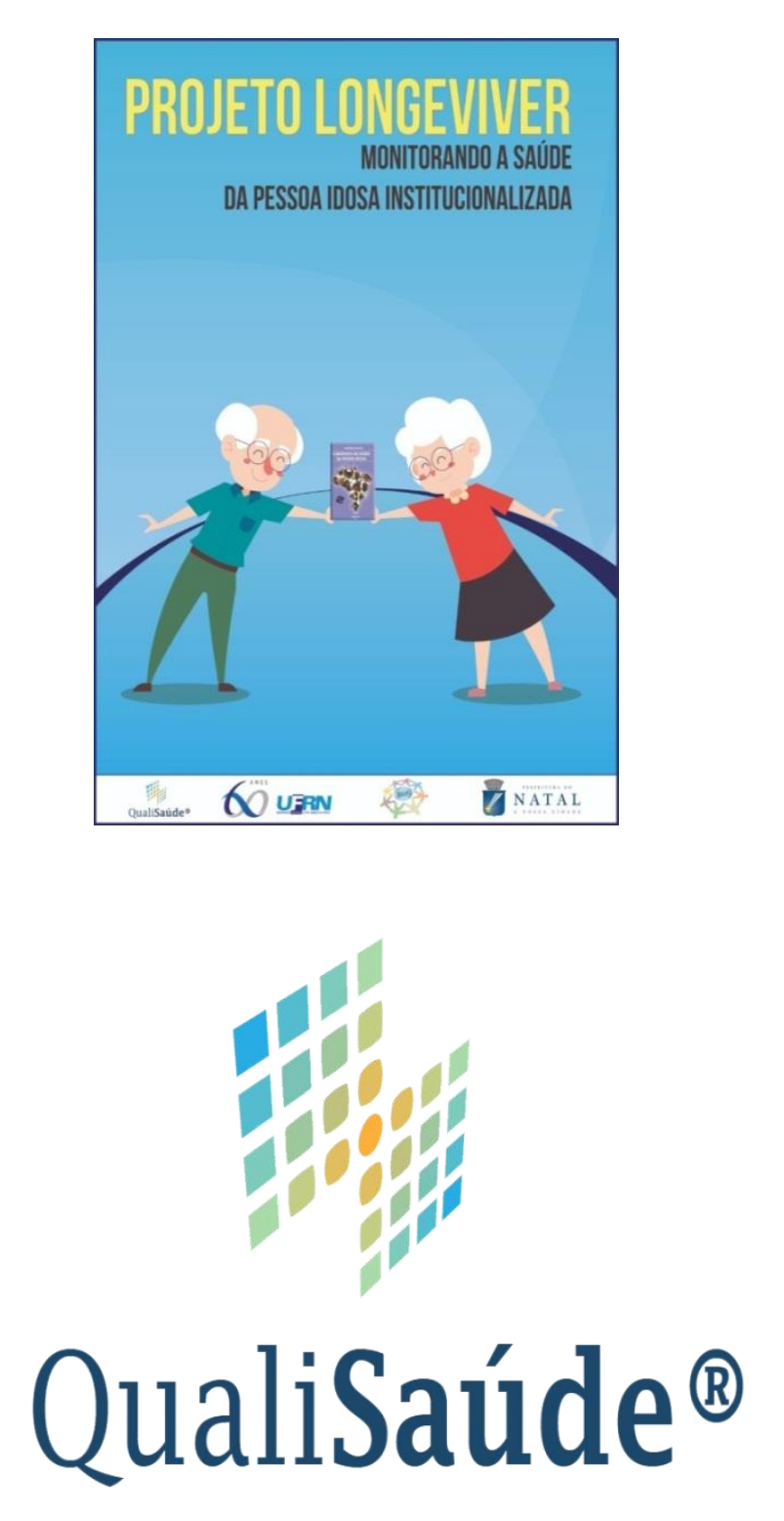

\section{INTRODUÇÃO}

A avaliação multidimensional de saúde da pessoa idosa deve contemplar os aspectos sociais, clínica, mental e funcional, e contribuir na identificação do conjunto das necessidades do idoso, possibilitando a otimização da alocação de recursos e estratégias de cuidado. Pensando assim, foi criada a caderneta de saúde da pessoa idosa, em 2014, com o intuito de identificar situações de risco para a saúde das pessoas idosas, informações sobre a sua condição de saúde, suporte familiar e social, fornecendo subsídios técnicos que ajudarão na qualificação da prática diária das equipes de saúde na melhoria da qualidade do cuidado à pessoa idosa.

\section{OBJETIVO}

Implantar e implementar a caderneta de saúde da pessoa idosa em instituições de longa permanência (ILP), de caráter público/filantrópico no município de Natal/RN.

\section{METODOLOGIA}

Estudo descritivo com abordagem quantitativa dividido em etapas.

Primeira etapa: Discussões sobre as estratégias de implementação da caderneta de saúde juntamente com a vigilância sanitária municipal, conselho municipal do idoso e os membros deste projeto.

Segunda etapa: Oficinas para capacitação dos profissionais das ILPI formando multiplicadores das ações.

Terceira etapa: Avaliação dos idosos institucionalizados pela equipe multiprofissional segundo os parâmetros da caderneta.

Quarta etapa: Digitalização e análises descritivas para produção de relatórios sobre as demandas de saúde dos idosos institucionalizados.

\section{RESULTADOS}

Foram implantadas e implementadas 213 cadernetas em 100\% das ILPI do município de Natal/RN, num total de 6 instituições de caráter filantrópico.
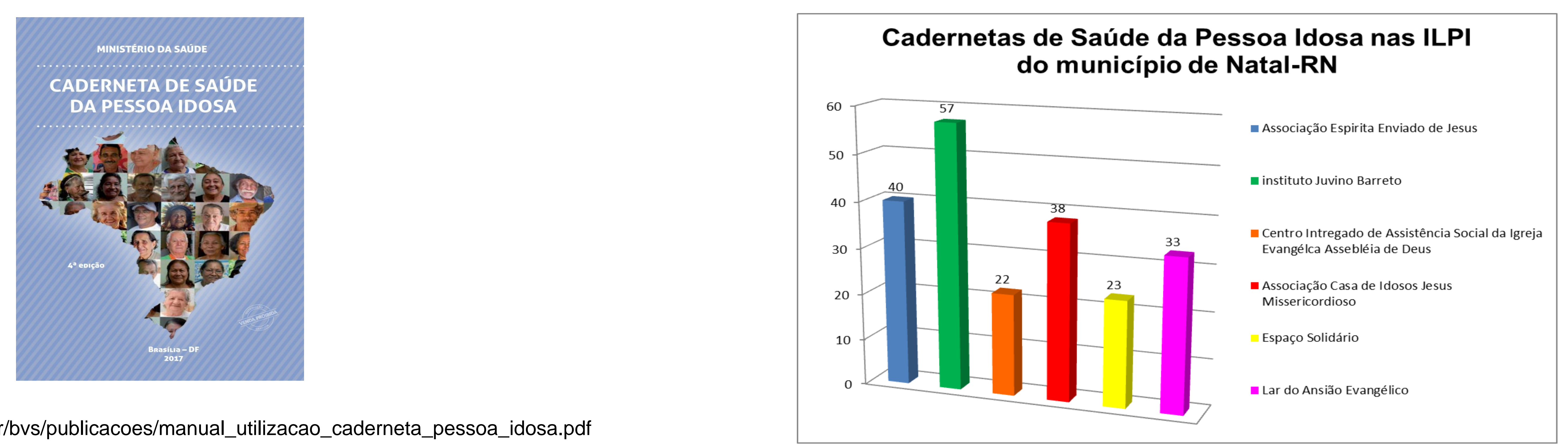

http://bvsms.saude.gov.br/bvs/publicacoes/manual_utilizacao_caderneta_pessoa_idosa.pdf

Número de Cadernetas implantadas em cada ILPI. Natal-RN, 2018.

\section{CONCLUSÃO}

A implementação da caderneta de saúde da pessoa idosa institucionalizada possibilitou estabelecer indicadores sobre as condições de saúde, e os possíveis riscos de desenvolver agravos sendo, portanto, fundamental para o acompanhamento do idoso na Estratégia de Saúde da Família com resolutividade no SUS.

\section{REFERÊNCIAS:}

1. BRASIL. Ministério da Saúde. RDC № 283, de 26 de setembro de 2005.

2. MINISTÉRIO DA SAÚDE. 1 ed. Brasília: All Type Assessoria Editorial Ltda, 2014. 46 p.

Disponível em: http://bvsms.saude.gov.br/bvs/publicacoes/diretrizes cuidado pessoa idosa sus.pdf. Acesso em: 08 mar. 2019. 